\title{
La neutralidad del Impuesto General \\ a las Ventas en el desarrollo de proyectos bajo la modalidad de Obras por Impuestos
}

\author{
The neutrality of the General Sales Tax \\ in the development of projects under \\ the Public Works Tax Deduction Law
}

\author{
Gonzalo Alonso Escalante Alpaca \\ Universidad Católica San Pablo, Arequipa, Perú \\ gaescalante@ucsp.edu.pe
}

\section{Resumen}

Esteartículo analiza la forma en la cual la neutralidad, entendida como el elemento que permite que la carga impositiva constituida por el Impuesto General a las Ventas (IGV) es trasladada al consumidor final mediante la figura del crédito fiscal y aplicada en el desarrollo de proyectos bajo la modalidad de Obras por Impuestos (OXI). Ello considerando que, en los informes o31-2010-SUNAT/2Boooo y 049-2010-SUNAT/2Boooo, la Administración Tributaria establece procedente la aplicación del crédito fiscal por las adquisiciones gravadas con IGV que realiza la empresa ejecutora de este tipo de proyectos. Se ha efectuado una investigación del tipo jurídico-propositivo que analiza al crédito fiscal, así como los pronunciamientos emitidos por la Administración Tributaria, la jurisprudencia del Tribunal Fiscal y los comentarios de la doctrina especializada, los mismos que nos permitieron determinar si estamos o no ante un supuesto en el cual procede la utilización del crédito fiscal por la empresa a cargo del proyecto; concluyendo, en nuestro análisis, que no resulta técnicamente correcto aceptar la configuración del crédito fiscal por las adquisiciones que realiza una empresa para efecto del desarrollo de un proyecto mediante el mecanismo de OXI.

\section{Palabras clave}

Impuesto General a las Ventas - neutralidad - Obras por Impuestos - crédito fiscal

\begin{abstract}
This article analyzes the way in which neutrality, understood as the element that allows the burden from the General Sales Tax (IGV, by its acronym in Spanish) to be transferred to the final
\end{abstract}


consumer through the tax credit institution, is applied in the development of projects under the mechanism of Works for Taxes (OXI, by its acronym in Spanish). This considering that in the reports 031-2010-SUNAT/2Boooo and 049-2010-SUNAT/2Boooo the Tax Administration established that the tax credit configured by the IGV taxed on the acquisitions made by the company in charge of the project can be applied as tax credit. There has been an investigation of the legal purpose kind which analyzes the configuration of the tax credit, as well as the pronouncements issued by the Tax Administration, the jurisprudence of the Tax Court and the comments of the specialized doctrine that allowed us to determine whether or not we are facing a scenario in which the use of tax credit by the company in charge of the project is feasible, concluding that it is not technically correct to consider the tax credit to be configured by the acquisitions made by a company for the purpose of developing a project through the OXI mechanism.

\section{Keywords}

Sales tax - neutrality - Works for Taxes - tax credit

\section{Introducción}

El IGV,denominado Impuestoal Valor Agregado (IVA) en otras jurisdicciones, grava las siguientes operaciones en Perú, según lo dispuesto en el artículo 1 del Texto Único Ordenado de la Ley del Impuesto General a las Ventas e Impuesto Selectivo al Consumo - Decreto Supremo 055-99-EF (Ley del IGV): i) la venta de bienes muebles en el país, ii) la prestación outilización de servicios en el país, iii) la importación de bienes, iv) los contratos de construcciónyv) la primera venta de un bien inmueble realizada por el constructor.

El IGV está diseñado de forma tal que las etapas intermedias del proceso productivo sean neutrales a imposición alguna y la carga impositiva sea traslada al último adquirente de la cadena decomercialización, denominadoconsumidor final. La legislación del IGV recoge el criterio de neutralidad dentro de los artículos 18 al 25 de la Ley del IGV, al establecer un sistema de impuesto contra impuesto, mediante el cual el IGV que sea pagadoen laadquisición de bienes y servicios (crédito fiscal), pueda ser aplicado contra el IGV originado por las futuras operaciones gravadas que realice un determinado contribuyente (débito fiscal).

El crédito fiscal, que permite la configuración de la neutralidad en la imposición del IGV, podrá ser utilizado siempre que se vincule a operaciones o transacciones gravadas con el impuesto y que sean calificadas como costo o gasto deducible para efectos del Impuesto a la Renta y en tanto el comprobante esté anotado en los registros contables del contribuyente. El crédito fiscal obtenido por un contribuyente, y que no sea utilizado en el mes que se generó, podrá ser utilizado en los meses siguientes.

Porotrolado, el Sistemade Obras por Impuestos (OXI), aprobado mediante Ley 29230, impulsa la inversión pública regionaly local con la participación del sector privado. El objetivo de la norma en mención es que los sujetos privados intervengan en forma directa en la ejecución de obras prioritarias para el Estado.

El sistema de OXI permitea los sujetos pertenecientesal sector privadodesarrollar proyectos en 
materia de salud, educación, turismo, agriculturay riego, orden públicoy seguridad, cultura, saneamiento, electrificación rural, industria, turismo, pesca, deporte, ambiente, remediación de pasivos ambientales, habilitación urbana, protección social, desarrollo social, transportes, comunicaciones, justicia, acceso a servicios de atención al ciudadano, mercado de abastos, incluyendo su mantenimiento.

Como consecuencia de la realización de proyectos bajo el mecanismo OXI, las empresas privadas se benefician con la obtención de un «Certificado de Inversión Pública Regional y Local - Tesoro Público» (CIPRL) o un «Certificadode Inversión Pública Gobierno Nacional - Tesoro Público» (CIPGN). Estoscertificados le permitirán a la empresa beneficiaria recuperar el monto invertido en la ejecución de los proyectos de inversión mediante su aplicación contra el Impuesto a la Renta de Tercera Categoría, que es la categoría del impuesto aplicable a los contribuyentes que desarrollan actividades empresariales, hasta por un porcentaje máximo del cincuenta por ciento $(50 \%)$ de dicho impuesto correspondiente al ejercicio anterior, según lo dispuesto expresamente en el numeral 7.2 del artículo 7 de la Ley 29230.

La Administración Tributaria, mediante los pronunciamientos recogidos en los informes 031-2010-SUNAT/2Boooo y 049-2010-SUNAT/2Boooo, ha establecido que los contratos de obra suscritos por una empresa para el desarrollo de un proyecto de OXI a su cargo se configuran como costo o gasto para efectos del Impuesto a la Renta, por lo que dan derecho a la empresa a utilizar como crédito fiscal el IGV generado por dichas operaciones.

Nohemosidentificadoalgún estudioqueanalice la configuración del crédito fiscal respectoa las adquisiciones que se lleven a cabo con motivo de la ejecución de un proyecto de OXI. Por lo tanto, nos hemos propuestoanalizar si efectivamente se configura el crédito fiscal en estecaso, considerando que este no es sino la forma en la cual se materializa la neutralidad dentro de la estructura del IGV.

Dentro de este análisis, nuestra hipótesis es que en tanto la ejecución de proyectos bajo el mecanismo de OXI no tenga como fin la realización deoperaciones afectas al IGV, no resulta procedente considerar que las adquisiciones llevadas a cabo con motivo de estos proyectos sean susceptibles degenerar crédito fiscal a favor de las compañías que los ejecutan.

El presenteartículodesarrolla una investigación jurídico-propositiva centrada en la institución legal del crédito fiscal y su vinculación con el desarrollo de proyectos de infraestructura a través de la modalidad de OXI. Se emplea el método hipotético-deductivo, con el fin de establecer la veracidad o no de la hipótesis.

Se procedió con la revisión de los elementos conformantes del criterio de neutralidad y de la institución del crédito fiscal, y con el análisis de los pronunciamientos de la Administración Tributaria contenidos en los informes 031-2010-SUNAT/2Boooo y o49-2010-SUNAT/2Boooo. Seguidamente, se contrastaron los argumentos expuestos en estos informes respecto a la aplicación del crédito fiscal, con los argumentos que recogen la doctrina especializada y el Tribunal Fiscal, para establecer cuándo procede la aplicación de la figura del crédito fiscal y su vinculación con el criterio de neutralidad. Se concluye el análisis señalando que los pronunciamientos emitidos por la Administración Tributaria, a través delos informes 031-2010-SUNAT/2Boooo 
yo49-2010-SUNAT/2Boooo, noresultanadecuados ni coherentesconel criteriodeneutralidady, en consecuencia, tampoco con la estructura del IGV, porloqueseproponequelaAdministración Tributaria deje sin efecto ambos informes.

\section{La neutralidad en el diseño del IGV}

Comoseplantea en la introducción del presente artículo, el IGV está diseñado con el objeto de trasladar la carga impositivaal consumidor final del producto o servicio. Es pues, un impuesto que grava el consumo como hecho que implica una manifestación de capacidad contributiva.

Para alcanzar este objetivo se incluye, dentro de la legislación peruana referente al IGV, el elemento de neutralidad que se hace efectivo mediante la técnica de impuesto contra impuesto, con lacual el débito fiscal (constituido porel IGVa pagar por una empresa con motivo de la realización de operaciones afectas a este impuesto) es compensado con el crédito fiscal (constituidoporel impuestopagadoencadauna delascomprasgravadasquesedierondurantelas etapas previasdelacadenadecomercialización).

Como consecuencia de la neutralidad antes descrita, se reduce o limita la existencia de distorsiones en las transacciones comerciales generadasporlaimposicióndel IGV. Distorsiones constituidascuandolossujetosqueforman parte de la cadena de comercialización asumen una carga impositiva por concepto de IGV, carga que debe trasladarseal consumidor final de los bienes o servicios comercializados.

Conforme a la legislación peruana, la determinación del IGV a pagar se realiza en forma mensual, por loque las compras gravadas deun determinado período (crédito fiscal) resultan aplicables contra las ventas gravadas con IGV del mismo período (débito fiscal) o períodos siguientes de ser el caso.

Para poder explicar deuna manera más sencilla la neutralidad del IGV, utilizamos comoejemplo el casodeuna empresa inmobiliariaquecontrata a terceros para quele presten el servicio deconstrucción de las unidades inmobiliarias queesta comercializa. Elloconformeal siguientedetalle:

Momento 1: La empresa inmobiliaria suscribe un contrato de obra con una constructora para que desarrolle un proyecto inmobiliario que implicalaconstruccióndediezunidadesinmobiliarias. La duración dela construcción es dediez meses, en los cuales se pagarán cuotas iguales. La transacción se da bajo las condiciones que se muestran en la tabla 1.

Tabla 1

\section{Condiciones del momento 1 de la transacción}

\begin{tabular}{|l|r|}
\hline Valor de venta del contrato de obra completa & $10,000,000$ \\
\hline IGV correspondiente al contrato de obra completa & $1,800,000$ \\
\hline Precio de venta final total del contrato de obra & $11,800,000$ \\
\hline Valor de venta de las cuotas mensuales del contrato de obra & $1,000,000$ \\
\hline IGV correspondiente a las cuotas mensuales del contrato de obra & 180,000 \\
\hline Precio de venta final por cada cuota mensual del contrato de obra & $1,180,000$ \\
\hline
\end{tabular}

Fuente: Elaboración propia. 
Conforme a la legislación correspondiente, el IGV pagado por la empresa inmobiliaria se constituyeen crédito fiscal para dicha entidad, mientras que para la empresa constructora se constituye en débito fiscal.

Momento 2: La empresa inmobiliaria vende las unidades inmobiliarias a terceros consumidores finales. Las ventas se realizan bajo la modalidad de venta de bien futuro, percibiendo pagos parciales o totales durante el lapso en el cual se lleva a cabo el proyecto de construcción por parte de la empresa constructora. La operación de venta se da bajo las condiciones que se muestran en la tabla 2

El IGV pagado por los adquirentes (consumidores finales) no puede ser utilizado por estos como crédito fiscal, en tanto no realizan operaciones afectas a dicho impuesto. No obstante, el IGV se configura como débito fiscal para la empresa inmobiliaria que está obligada a tributar por dicho impuesto.

Ahora bien, para establecer la cuantía de la deuda tributaria mensual por concepto de IGV que le corresponde asumir a la empresa inmobiliaria (débito fiscal), deberá calcular el IGV generado por sus operaciones de venta de unidades inmobiliarias y aplicar contra este monto el IGV generado por sus operaciones de adquisición de bienes y/o servicios (crédito fiscal) del mismo periodo o saldos de períodos anteriores vinculados a la generación de operaciones gravadas. Esto último considerando que, si en un período existe un crédito fiscal superior al débito, podrá ser utilizado en los meses siguientes hasta su agotamiento.

De esta manera, si en el mes 1 de inicio de la obra la empresa inmobiliaria paga una cuota a la constructora por S/ 1,00o,ooo, deberá pagar en este periodo un IGV por S/ 180,ooo.

Si en este mes realiza también la venta de un departamento bajo la figura de venta de bien futuro, que le implica a la empresa inmobiliaria la percepción del precio de venta total, tenemos que generaría un ingreso por $\mathrm{S} / 1,500,000$ y un IGV por pagar al fisco equivalente a S/ 135,00o. Sin embargo, en aplicación del principio de neutralidad sabemos queal débito fiscal por $S / 135,000$ se le restará el crédito fiscal de $\mathrm{S} / 180,000$ generado en el mismo período, y como resultado se tendría un saldo por crédito fiscal de $\mathrm{S} / 45$, ooo que la empresa inmobiliaria podrá arrastrar a los

Tabla 2

Condiciones del momento 2 de la transacción

\begin{tabular}{|l|r|}
\hline Valor de venta total de las diez unidades inmobiliarias & $15,000,000$ \\
\hline IGV por la venta total de las diez unidades inmobiliarias* & $1,350,000$ \\
\hline Precio de venta total de las diez unidades inmobiliarias & $16,350,000$ \\
\hline Valor de venta unitario por cada una de las unidades inmobiliarias & $1,500,000$ \\
\hline IGV aplicable por la venta de cada una de las unidades inmobiliarias & 135,000 \\
\hline Precio de venta por cada una de las unidades inmobiliarias & $1,635,000$ \\
\hline
\end{tabular}

* Esta operación se encuentra gravada por tratarse de la primera venta efectuada por el constructor, siendo que la base imponible afecta con IGV es el equivalente al 50\% del valor de venta.

Fuente: Elaboración propia. 
meses siguientes hasta su agotamiento, sin

El ejemplo se ilustra en la figura 1. que en el mes 1 se haya generado la obligación de cumplir con pago alguno a favor del fisco por concepto de IGV.

\section{Figura 1}

\section{Criterio de neutralidad inherente a la estructura del IGV}

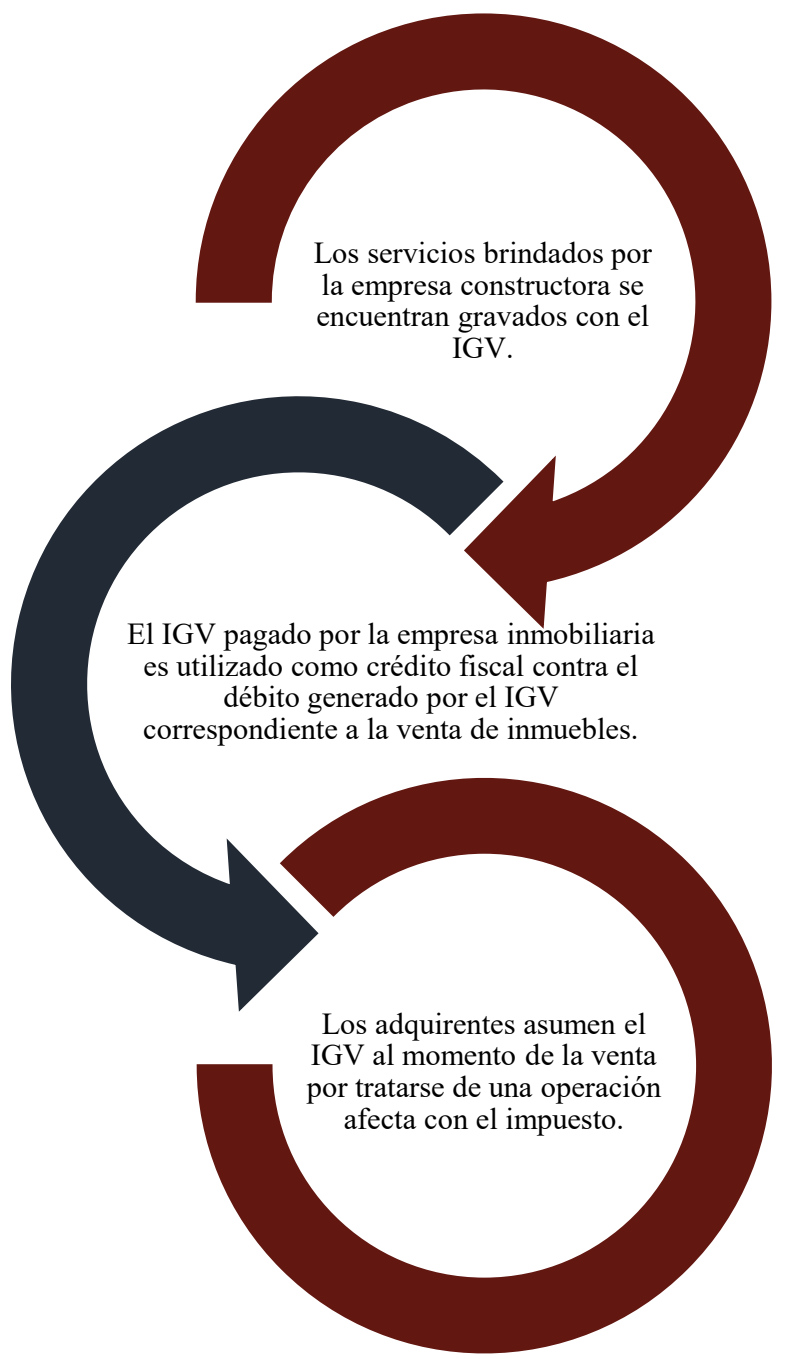

Fuente: Elaboración propia. 
Así pues, el IGV que le corresponde tributar a la empresa inmobiliaria por la enajenación de unidades inmobiliarias seve reducido por el crédito fiscal que se generó como consecuencia del IGV cancelado por el contrato de obra suscrito con la empresa constructora.

Sobre la neutralidad y su configuración respecto al IGV, Villanueva (2014) señala lo siguiente:

En la concepción del IGV como impuesto que grava cada operación concreta de intercambio de bienes y servicios empresariales es absolutamente indiscutible que la base imponible del impuesto es la contraprestación que se recibe a causa de la venta o prestación de servicios. La contraprestación como la base imponible de la operación gravada es la suma total que queda obligado a pagar el adquirente por razón de la operación de la que se trate, $[. .$.$] el nacimiento de la$ obligación tributaria [...] y la alícuota [...] presuponen que el hecho gravado es la venta de bienes y prestación de servicios. (p. 296).

[...] el derecho al crédito fiscal se concede al sujeto del impuesto para la satisfacción de un interés típico, que consiste en el reembolso económico del impuesto pagado en razón de sus adquisiciones gravadas con el impuesto. (p. 297).

Respecto al diseño del IGV, Bravo (2018) indica que: «De acuerdo a la estructura técnica de nuestro IGV, para obtener ese valor agregado que es su objeto de imposición debe utilizarse el método de sustracción sobre base financiera de tipo impuesto contra impuesto, que consiste en detraer de los débitos fiscales de las operaciones activas realizadas en un período mensual (las ventas), los créditos fiscales de las operaciones pasivas (las compras)» (p. 25).

A mayor abundamiento, Agüero (2016) señala que:

[...] La utilización del crédito fiscal ocasiona que el Impuesto General a las Ventas incida, finalmente, sobre quien debe incidir: el consumidor final. La afectación del impuesto al valor agregado conlleva a que deba haber recaudación únicamente donde ocurra el consumo final y no antes. El Crédito Fiscal impide además que el Impuesto General a las Ventas se convierta en un impuesto ciego a los ingresos, generando efectos confiscatorios por superposición al Impuesto a la Renta. (p. 394).

Así pues, a partir de estas consideraciones, la neutralidad dentro del diseño del IGV implica que el débito fiscal se verá necesariamente compensado contra el crédito fiscal obtenido por la adquisición de bienes y servicios gravados con el impuesto. La finalidad de realizar adquisiciones afectas al IGV deber ser la realización de operaciones que estarán a su vez gravadas con este impuesto, ya que ello se configura como un supuesto condicionante para alcanzar la referida neutralidad mediante la utilización del crédito fiscal.

En este orden de ideas, cabe mencionar que la Administración Tributaria mediante el informe 27-2016-SUNAT/5A1ooo ha 
indicado que el IGV contiene las siguientes características:

a. Es un impuesto no acumulativo. Por esta característica, el IGV se aplica solo sobre el valor agregado en cada etapa de la comercialización o distribución de los bienes y servicios y no sobre el total del valor de venta.

b. Aplica el método del crédito sustractivo indirecto (impuesto contra impuesto). Bajo este método, el monto del impuesto que un contribuyente declaray paga es la diferencia entre el impuesto que recauda de sus ventasy el impuesto que ha soportado por adquisiciones, actuando solo como agente recaudador.

c. Aplica la modalidad de base financiera, que supone que la materia imponible se obtiene por diferencia entre las ventas y las compras realizadas en un período determinado, sin relacionar directamente las ventas con los insumos empleados y sin considerar los niveles de inventarios existentes al cierre del periodo fiscal.

d. Es plurifásico porque se aplica prácticamente a todas las etapas del ciclo de producción y distribución, desde el productor o importador inicial hasta el consumidor final que de acuerdo al diseño del tributo es quien soporta la carga del impuesto.

El Tribunal Fiscal en la resolución 044883-2015 señala:

Que al respecto, este Tribunal ha sostenido en reiteradas resoluciones, que el Impuesto General a las Ventas en el
Perú constituye un tipo de imposición al consumo estructurado bajo la técnica del impuesto al valor agregado, con el método de sustracción sobre la base financiera, en la variable de impuesto contra impuesto, siendo de liquidación mensual, y que la estructura de nuestra legislación admite, como consecuencia, deducciones amplias de los bienes del circuito de consumo que los sujetos adquieran para el desarrollo de sus actividades, sean estos insumos que se integren físicamente al bien, que se consuman en el proceso, gastos de la actividad, o activos fijos, y que asimismo, es un sistema de deducciones inmediatas que permite la deducción del total del impuesto que gravó las adquisiciones en el período en que se efectúa la adquisición sin necesitar que éstas sean en tal período efectivamente incorporadas en el proceso de venta, comercialización o servicio.

En tal sentido, según el criterio expuesto por la Administración Tributaria y el Tribunal Fiscal citados en los párrafos precedentes, resulta evidente que la única forma de llegar a la neutralidad en la aplicación del IGV es si se aplica crédito fiscal obtenido por las compras gravadas con el IGV contra el débito por pagar generado por las operaciones gravadas con dicho impuesto en un determinado período, resultando necesario que las adquisiciones sean empleadas para la realización de operaciones afectas al impuesto.

\section{El destino de las adquisiciones afectas al IGVy su vinculación con el crédito fiscal}

Conforme a lo comentado previamente, uno de los requisitos sustanciales para la 
utilización del crédito fiscal es queel impuesto pagado por una determinada empresa corresponda a bienes y servicios que, a su vez, van a ser empleados para la realización de operaciones gravadas.

La Ley del IGV ha recogido en su artículo 18 los siguientes requisitos sustanciales que deben cumplir las adquisiciones de bienes y servicios para que resulte procedente la utilización del IGV que las gravó como crédito fiscal:

- Que sean permitidos como gasto o costo de la empresa, de acuerdo a la legislación del Impuesto a la Renta, aun cuando el contribuyente no esté afecto a este último impuesto.

Tratándose de gastos de representación, el crédito fiscal mensual se calculará de acuerdo al procedimiento que para tal efecto establezca el Reglamento.

- Que se destinen a operaciones por las que se deba pagar el Impuesto.

Y en este sentido, el numeral 1 del artículo 6 del Reglamento de la Ley del IGV disponeque los bienes, servicios y contratos de construcción que se destinen a operaciones gravadas cuya adquisición o importación dan derecho a crédito fiscal son los siguientes:

- Los insumos, materias primas, bienes intermediosy servicios afectos, utilizados en la elaboración de los bienes que se producen o en los servicios que se presten.

- Los bienes de activo fijo, tales como inmuebles, maquinarias y equipos, así como sus partes, piezas, repuestos y accesorios.
- Los bienes adquiridos para servendidos.

- Otros bienes, servicios y contratos de construcción cuyo uso o consumo sea necesario para la realización de las operaciones gravadas y que su importe sea permitido deducir como gasto o costo de la empresa.

Sobre este punto, Villanueva (2014) menciona que: «El destino a operaciones gravadas requiere que la adquisición sirva para la realización de este tipo de operaciones». Y agrega:

Nuestra opinión es que la adquisición debe servir directa o indirectamente a la realización de una operación gravada. No influye en el examen de este requisito el destino de los fondos de una operación inafecta o exonerada para la realización de operaciones gravadas. La razón es que cualquier flujo de dinero proveniente de una operación inafecta o exonerada podría usarse para el desarrollo de actividades gravadas. (p. 302).

En este sentido, Delgado (2001) indica respecto a los requisitos sustanciales del crédito fiscal que:

En nuestra legislación, dichos requisitos sustanciales exigen que las adquisiciones de bienes o servicios se destinen a operaciones gravadas con el IGV y que teóricamente sean permitidas como costo o gasto del Impuesto a la Renta, esto es, que se dirijan a mantener la fuente productora de renta o a la generación de ingresos vinculados al giro del negocio. (p. 273). 
Padrón (2001), al analizar el requisito previsto en el inciso b) del artículo 18 de la Ley del IGV, indica que «nos conduce a que los contribuyentes que realicen operaciones gravadas y no gravadas con el impuesto, sólo tendrán derecho a aplicar el crédito fiscal por la parte que corresponde a operaciones gravadas» (p. 308).

Por consiguiente, y siguiendo el razonamiento expuesto por los citados autores, es que consideramos que solamente cuando las adquisiciones estén destinadas a realizar operaciones gravadas con el IGV es que se permitirá la utilización del crédito fiscal generado por el IGV pagado por dichas adquisiciones. Ello en directa observancia del criterio de neutralidad como elemento constitutivo de la estructura impositiva del IGV en nuestra legislación.

En tal sentido se ha pronunciado también el Tribunal Fiscal en la resolución o1788-82017 al indicar que:

[...] para no distorsionar la técnica del valor agregado y deducir el impuesto que efectivamente corresponde, la Ley del Impuesto General a las Ventas, establece dos requisitos sustanciales para que las adquisiciones de bienes, servicios y contratos de construcción otorguen derecho a la deducción del denominado crédito fiscal: a) que los bienes adquiridos sean costo o gasto para el Impuesto a la Renta; y, b) que dichos bienes sean destinados a operaciones gravadas. [...] el segundo requisito está referido a que solo debe tomarse como crédito fiscal la parte del impuesto pagado por adquisiciones destinadas a operaciones gravadas, pues solo por estas se determina el mayor valor por el cual debe pagarse el impuesto [...].

Así pues, en tanto una compra gravada con IGV no esté vinculada con una operación que va a encontrarse a su vez afecta al IGV, no se permitirá la utilización de crédito fiscal generado por la mencionada adquisición.

El Tribunal Fiscal mediante las resoluciones o6oo-1-2001, 01258-1-2004, 04940-2-2006 y 04488-3-2015, entre otras, ha reiterado el criterio antes expuesto, dejando claramente establecido que, conforme al requisito recogido en el inciso b) del artículo 18 de la Ley del IGV, el impuesto que grava las adquisiciones podrá aplicarse como crédito fiscal contra el débito fiscal constituido por el IGV aplicable a las operaciones de comercialización y venta que posteriormente realice un mismo sujeto, siempre que dichas adquisiciones estén vinculadas a la realización de operaciones afectas al IGV.

Al respecto, Córdova (2001) indica que:

En tal sentido, el crédito fiscal sólo se justifica si es que en la etapa posterior del ciclo de producción y comercialización existe impuesto a pagar, pues de lo contrario, de no encontrarse gravadas las etapas posteriores se elimina cualquier riesgo de piramidación del tributo que es el fundamento principal que justifica el derecho al crédito fiscal. (p. 254).

En este orden de ideas, la Administración Tributaria en el Informe o18-2014-SUNAT/4Boooo indica que: 
[...] en el momento de la realización de la adquisición de los bienes y servicios, contratos de construcción e importación, se debe determinar el destino inmediato de tales operaciones, para efectos del crédito fiscal del período, siendo que su deducción sólo se justifica si es que en la etapa posterior del ciclo de producción y comercialización la adquisición se destina a una operación gravada con el IGV.

Así pues, la Administración Tributaria reconoce como esencial el hecho que las adquisiciones que den mérito a la utilización del crédito fiscal deben estar necesariamente vinculadas a operaciones gravadas con el IGV. Dichas operaciones deben formar parte del ciclo de producción o comercialización de los bienes o servicios gravados, ya que de no ser así se estaría rompiendo la cadena de neutralidad en la aplicación de estegravamen sobre el valor agregado.

\section{El crédito fiscal obtenido por el desa- rrollo de proyectos a través del sistema de OXI}

En el presente apartado analizamos el criterio recogido por la Administración Tributaria respecto a la aplicación del crédito fiscal por las adquisiciones realizadas en el desarrollo de un proyecto de OXI.

Así las cosas, tenemos que el informe 031-2010-SUNAT/2Boooo emitido por la Administración Tributaria establece que:

El IGV trasladado en la adquisición de bienes, servicios y contratos de construcción destinados al cumplimiento de los convenios suscritos al amparo de la Ley $\mathrm{N}^{\circ} 29230$ otorga derecho al crédito fiscal para el inversionista privado que financia y ejecuta un proyecto de inversión pública en infraestructura.

Por su parte, el informe 049-2010-SUNAT /2Boooo prevé que, con motivo del desarrollo de un proyecto de OXI, resulta procedente la utilización del crédito fiscal por las adquisiciones relacionadas con el mismo, señalando que:

$\mathrm{Al}$ existir entre la empresa constructora y la empresa privada que financia el proyecto de inversión una operación que se encuentra afecta al IGV, y a su vez, al constituir esta operación costo o gasto para fines del Impuesto a la Renta, se desprende que la empresa privada que financia el proyecto de inversión puede utilizar como crédito fiscal el IGV trasladado por la empresa constructora que contrató para la ejecución de la inversión.

Dentro de este informe se concluye que:

- La mera entrega del CIPRL no se encuentra gravada con el IGV.

- La empresa privada que financia el proyecto de inversión puede utilizar como crédito fiscal el IGV trasladado por la empresa constructora que contrató para la ejecución del proyecto de inversión.

Al respecto debemos indicar que el informe 190-2019-SUNAT/7Toooo, en su cuarta nota al pie, señala que: 
Es del caso mencionar que en el informe 049-2010-SUNAT/2Boooo, [...] se ha señalado que la mera entrega del CIPRL que sirve para cancelar el monto invertido por la empresa privada en la ejecución de los proyectos de inversión (y que finalmente es la contraprestación debida) no se encuentra gravada con el IGV, al no constituirse propiamente en una venta de un bien mueble o ser en sí misma una prestación de servicios u otro tipo de operación incluida en el ámbito de aplicación de dicho tributo, sino en un medio de pago de la acreencia a favor de la empresa privada.

Así pues, tenemos que los informes o31-2o10-SUNAT/2Boooo y o49-2010-SUNAT/2Boooo contienen un análisis basado en el requisito previsto en el inciso a) del artículo 18 de la Ley del IGV, para concluir en ambos casos que los contratos suscritos para la concreción de un proyecto por OXI se constituyen como un costo o gasto deducible para la determinación del Impuesto a la Renta y, como consecuencia de ello, dan derecho a la empresa a cargo del proyecto a utilizar como crédito fiscal el IGV pagado por las adquisiciones efectuadas para la ejecución de la obra. En ninguno de los pronunciamientos se realiza un análisis adecuado y suficiente respecto al cumplimiento del inciso b) del artículo 18 de la Ley del IGV, para que se pueda considerar como procedente la utilización de crédito fiscal alguno por las adquisiciones llevadas a cabo dentro del marco del desarrollo de un proyecto de OXI.

De los informes bajo comentario, se obtiene también que se considera a la ejecución de los proyectos de OXI como operaciones gravadas con el IGV bajo el concepto de contratos de construcción recogido en el inciso c) del artículo 1 de la Ley del IGVy en el inciso f) del artículo 3 del mismo cuerpo normativo; donde se conceptualiza a los contratos de construcción como aquellos por los que se acuerda la realización de las actividades clasificadas como construcción en la Clasificación Internacional Industrial Uniforme (CIIU).

La figura legal del contrato de construcción conforme a la legislación del IGV se configura únicamente respecto a la subcontratación que puede realizar una empresa suscriptora de un convenio de OXI con una tercera compañía para que desarrolle parte o todo el proyecto, mas no entre la empresa suscriptora del convenio y la entidad estatal con la que lo suscribe.

El desarrollo de los proyectos de infraestructura en el marco de la normativa de OXI y las adquisiciones vinculadas a los mismos, no tienen como consecuencia la obtención de ingreso alguno afecto al IGV, ya que la empresa privada una vez que concluya el proyecto cede la administración de la obra al Estado sin recibir beneficio económico alguno como consecuencia de tales proyectos, por lo que no existe contraprestación sobre la base de la cual pueda determinarse obligación tributaria alguna respecto al IGV.

Debemos tener en consideración que una vez entregado el proyecto, el único beneficio para la empresa que lo desarrolló va a ser la obtención del correspondiente CIPRL o CIPGN que será utilizado para la deducción del Impuesto a la Renta, sin 
que se obtenga como consecuencia de ello algún ingreso afecto al IGV. El desarrollo de los proyectos a través del mecanismo de OXI no va a significar la obtención de una ventaja económica para la empresa a cargo del proyecto correspondiente ni implica la existencia de una operación con un valor agregado subyacente.

Es decir, una vez realizada la inversión, la empresa que llevó a cabo la misma no podrá utilizar esta obra para su explotación económica ni para la generación de rentas gravadas, ni operaciones afectas al IGV. Ello, por cuanto el proyecto será puesto a disposición de la entidad estatal con la cual se suscribió el convenio y será esta a la que le corresponderá utilizar la obra resultante de la ejecución del proyecto para los fines que resulten pertinentes.

Es por ello que consideramos que el tratamiento recogido en los informes 031-2010-SUNAT/2Boooo y o49-2010-SUNAT/2Boooo, respecto a la utilización del crédito fiscal con motivo del desarrollo de proyectos de OXI, significa una desnaturalización de la figura del crédito fiscal y una contravención a la estructura misma del tributo, en tanto que se fuerza la figura de la neutralidad en la estructura del IGV respecto a adquisiciones que, si bien están gravadas con el IGV, no están destinadas a operaciones afectas con dicho impuesto.

No podemos considerar que el análisis efectuado dentro de los informes de la Administración Tributaria referidos sea el correcto, ya que no se considera en forma alguna que en el caso bajo análisis no existe una posterior venta de bienes ni prestación de servicio que pueda significar, para la empresa encargada de llevar a cabo el proyecto vía OXI, la obtención de un ingreso gravado con IGV.

Un supuestodistinto es quela Administración Tributaria considere que las adquisiciones realizadas para el desarrollo de un proyecto de OXI resulten deducibles respecto al Impuesto a la Renta al calificarlos como costo o gasto, ya que en este caso entran a calar otros criterios de más amplia configuración como el principio de causalidad, pero es un supuesto muy distinto pretender avalar la aplicación de un crédito fiscal que va a significar la deducción de la carga impositiva por concepto de IGV por adquisiciones que no se encuentran destinadas al desarrollo de operaciones gravadas con dicho impuesto. La incongruencia del planteamiento del fisco, contenido en los citados informes, se hace más evidente si tomamos en consideración que en la conclusión 4 del informe o49-2010-SUNAT/2Boooo se consigna en forma expresa que la mera entrega del CIPRL no se encuentra gravada con el IGV, por lo que ni siquiera podría considerarse el monto de los certificados como valor de la construcción para efecto de determinar, sobre la base de este monto, la carga impositiva aplicable por concepto de IGV.

Es pues sobre la base de los argumentos antes expuestos que, a nuestro criterio, no debe considerarse como procedente la aplicación del crédito fiscal como consecuencia de los contratos suscritos por una empresa ejecutora de un proyecto de OXI, por más que estos puedan ser considerados o no como deducibles para efecto de la determinación del Impuesto a la Renta, ya que en tanto el desarrollo del proyecto de OXI no tenga como objeto la realización de operaciones 
gravadas con el IGV, no resulta aplicable crédito fiscal alguno. Asumir una postura contraria implica desnaturalizar la neutralidad que debe estar presente en la estructura impositiva del IGV para no generar una distorsión en el mercado.

Por lo tanto, correspondea la Administración Tributaria efectuar una revisión de los informes 031-2010-SUNAT/2Boooo y 049-2010-SUNAT/2Boooo; en tanto las conclusiones a las cuales se arribaron, en ambos documentos, no resulta coherente con la naturaleza del criterio de neutralidad inherente a la estructura del IGV.

Habiendo dicho ello, consideramos necesario graficar nuestra posición a efecto de que sea más fácil su lectura y permita identificar en forma clara por qué consideramos que el IGV pagado en la adquisición de bienes y servicios para el desarrollo de un proyecto de OXI no califica como crédito fiscal, pese a lo que equivocadamente indica la Administración Tributaria mediante los informes analizados. Nuestra posición se ilustra en la figura 2.

\section{Resultados}

Como consecuencia del análisis efectuadoy el contraste realizado entre los pronunciamientos contenidos en los informes emitidos por Administración Tributaria con la jurisprudencia y la doctrina especializada, se obtiene que el crédito fiscal resulta aplicable siempre que, entre otros requisitos, el IGV que lo genera haya sido pagado respecto a bienes o servicios vinculados directamente a operaciones afectas con este impuesto.

Figura 2

IGV pagado en la adquisición de bienes y servicios de OXI no califica como crédito fiscal

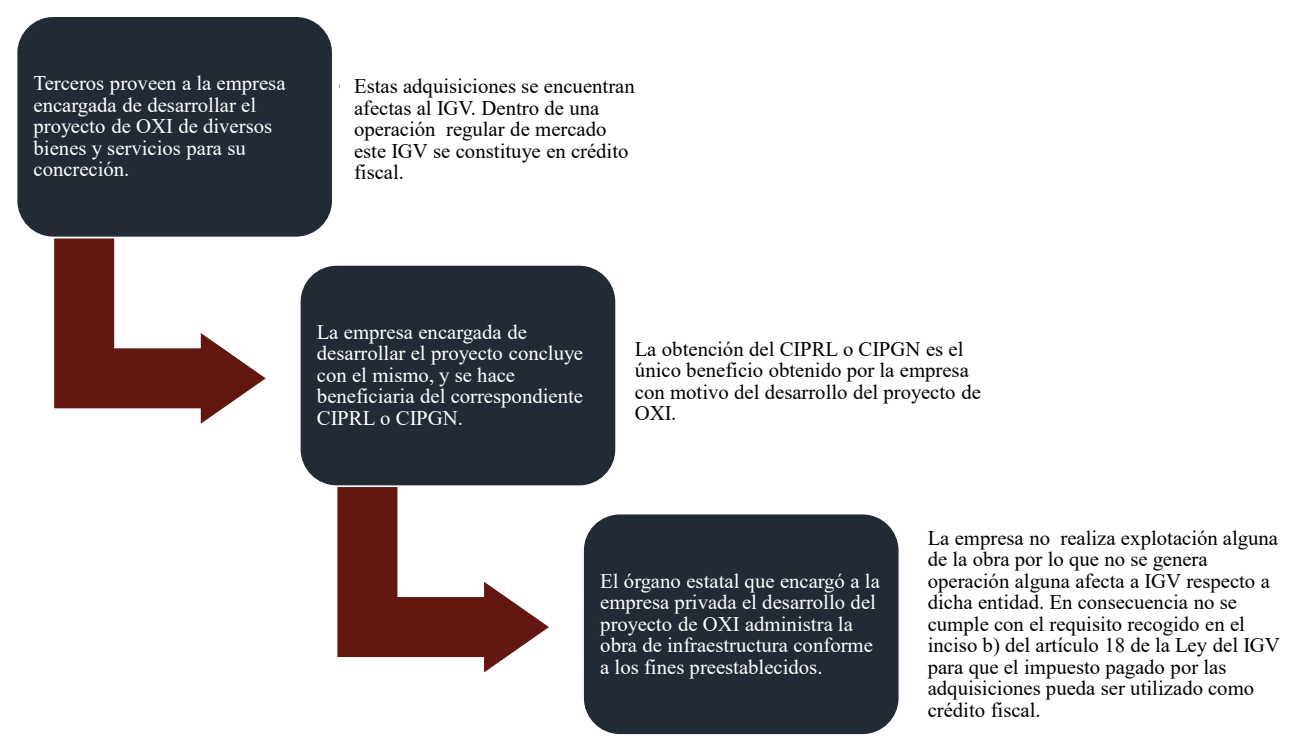

Fuente: Elaboración propia. 
Siendo así, no resulta aplicable el crédito fiscal cuando las adquisiciones no tienen como objeto desarrollar operaciones gravadas.

Ello debido al criterio de neutralidad que forma parte neurálgica de la estructura del IGV conforme a nuestro ordenamiento jurídico, que implica la utilización de la técnica de impuesto contra impuesto, mediante la cual un crédito fiscal obtenido por la adquisición de bienes y servicios gravados con IGV se aplicará contra el débito fiscal generado por la realización de operaciones afectas a dicho impuesto.

Por lo tanto, si al desarrollarse un proyecto de infraestructura dentro del marco regulatorio de OXI no se va a producir ningún hecho económico que implique una afectación con el IGV, es que no resulta procedente la utilización del IGV de las adquisiciones de bienes y servicios necesarios para el desarrollo del proyecto de infraestructura como crédito fiscal.

Así pues, las conclusiones de los informes 031-2010-SUNAT/2Boooo y 049-2010-SUNAT/2Boooo no resultan acordes con el criterio de neutralidad, por lo que su reconocimiento y aplicación genera una desnaturalización del mencionado criterio debiendo dejarse a ambos sin efectos.

\section{Conclusiones}

Conformeal análisis realizado hemos podido establecer que el inciso b) del artículo 18 de la Ley del IGV recoge el criterio de neutralidad como requisito sustancial para la procedencia de la utilización del crédito fiscal. Ello implica que el crédito fiscal podrá ser utilizado siempreque las adquisiciones de bienes y servicios afectos con IGV se encuentren destinadas a la realización de operaciones gravadas con el impuesto.

Por otro lado, tenemos que la adquisición de bienes y servicios para el desarrollo de proyectos de OXI no está destinada a la realización de operaciones gravadas con el IGV. Así como la suscripción de un convenio para el desarrollo de un proyecto de OXI no implica la configuración de un proyecto de construcción afecto al IGV, pues ello significaría que la empresa, luego de concluido el proyecto, pueda explotarlo para el desarrollo de operaciones gravadas con el impuesto. Escenario que no se condice con el mecanismo de OXI.

El reconocer que las adquisiciones llevadas a cabo por la empresa suscriptora de un convenio para llevar a cabo un proyecto de OXI permiten utilizar el IGV pagado como crédito fiscal implica desnaturalizar la neutralidad como elemento inherente al diseño del IGV.

Por lo antes expuesto, corresponde que la Administración Tributaria realice una revisión de los criterios expuestos en los informes 031-2010-SUNAT/2Boooo y o49-2010-SUNAT/2Boooo, a efecto de verificar que los mismos no resultan técnicamente correctos para proceder a dejarlos sin efectos.

\section{Referencias}

Agüero, A. (2016). El requisito del costo o gasto para efectos del IR en la utilización del crédito fiscal. En Guía Tributaria Contable y Análisis Jurisprudencial. Lima: Thomson Reuters. 
Bravo, J. (2018). Teoría sobre la Imposición al Valor Agregado. Lima: Palestra.

Córdova, A. (2001). Requisitos sustanciales del crédito fiscal. VII Jornadas Nacionales de Derecho Tributario. http://www.ipdt.org/uploads/docs/o9_ Rev\%2041_ACA.pdf

Delgado, C. (2001). Crédito fiscal: Requisitos formales y operaciones no reales. VII Jornadas Nacionales de Derecho Tributario. http://www.ipdt.org/ uploads/docs/10_Rev41_CDR.pdf

Padrón, C. (2001). Algunas precisiones sobre la aplicación de la técnica del valor agregado y los requisitos sustantivos del crédito fiscal previstos en la legislación. VII Jornadas Nacionales de Derecho Tributario.

Villanueva, W. (2014). Tratado del IGV, Regímenes general y especiales. Lima: Pacífico.
Referencias jurisprudenciales y pronunciamientos de la Administración Tributaria

$\begin{array}{ll}- & \text { Informe o18-2014-SUNAT/4Boooo. } \\ - & \text { Informe 031-2010-SUNAT/2Boooo. } \\ - & \text { Informe 049-2010-SUNAT/2Boooo. } \\ - & \text { Informe 27-2016-SUNAT/5A10oo. } \\ - & \text { Informe 190-2019-SUNAT/7Toooo. } \\ - & \text { Resolución del Tribunal Fiscal } \\ & \text { o4488-3-2015. } \\ -\quad & \text { Resolución del Tribunal Fiscal } \\ & \text { o6oo-1-20o1. } \\ -\quad \text { Resolución del Tribunal Fiscal } \\ \\ \text { o1788-8-2017. } \\ \text { Resolución del Tribunal Fiscal } \\ \text { o1258-1-2004. } \\ \text { - Resolución del Tribunal Fiscal } \\ \text { o4940-2-2006. }\end{array}$

Fecha de recepción: 11 de septiembre de 2019 Fecha de aceptación: 28 de noviembre de 2019 